\section{African Inventory}

PAGES and the Pan African START Secretariat (PASS) noted during the recently held IGBP SAC V Meeting in Nairobi,

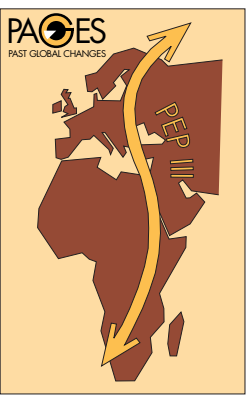

Kenya from September 1-7, 1998, that there is a wealth of paleoscience activities in Africa being carried out by African scientists.

This work is somewhat invisible to other researchers both in Africa and internationally. We would, therefore, like to conduct a survey of who is doing what and where, in order to strengthen information exchange and foster new collaborative links internationally. This information will be retained on a database, mounted on the PAGES Website, and published in the PASS Newsletter, which is circulated internationally.

We are requesting the PAGES community world wide to inform us about existing African paleoenvironmental research projects using the form on this page. Please return it to the address indicated on the form (by post, email or fax), as soon as possible, so that we can collate and distribute this information in early 1999.

The form is also available in an online-version at the PAGES Website: http://www.pages.unibe.ch/activities/ africaform.html.

\section{ERIC O. Odada}

Programme Director, Pan-African START Secretariat, University of Nairobi, Kenya pagesnbo@form-net.com

\section{INVENTORY OF AFRICAN PALEO-SCIENCE RESEARCHERS}

\begin{tabular}{|l|l|}
\hline Surname: & First Name: \\
\hline Initials: & Title: \\
\hline \multicolumn{1}{|c|}{ Office } & Home \\
\hline Address: & Address: \\
& \\
\hline Telephone: & Telephone: \\
\hline Facsimile: & Facsimile: \\
\hline Telex: & \\
\hline Email: & \\
\hline
\end{tabular}

Current Employment Position:

Academic Qualifications:

\begin{tabular}{|l|l|l|l|}
\hline Higher Degree: & Institution: & Subject(s): & Year: \\
\hline & & & \\
\hline Area of Interest (Geographical): & Area of Interest (Topical): \\
\hline & & \\
\hline & & \\
\hline
\end{tabular}

Current Research Activities/Projects:

Recent Publications (from 1993 to Present):

You may attach more detailed information on research activities/projects and recent publications and return the form to:

Pan-African START Secretariat (PASS) c/o Department of Geology, University of Nairobi

P O Box 30197

Nairobi, KENYA

Telephone: (+254-2) 447740

Facsimile: (+254-2) 449539

Email: pagesnbo@form-net.com 